\title{
Promovendo a Interação Mãe-Criança com Implante Coclear: Um Estudo de Caso ${ }^{1}$
}

\author{
Ana Carolina Villares Barral Villas Boas ${ }^{2}$ \\ Universidade de São Paulo \\ Olga Maria Piazentin Rolim Rodrigues \\ Universidade Estadual Paulista Julio de Mesquita Filho \\ Midori Otake Yamada \\ Universidade de São Paulo
}

\begin{abstract}
RESUMO - O objetivo deste estudo foi verificar os efeitos de uma intervenção conduzida com a mãe de uma criança com implante coclear através da avaliação de mudanças comportamentais identificadas após o programa. Participou deste estudo uma díade mãe ouvinte-criança com deficiência auditiva e implante coclear, filmada em quatro sessões de observação: uma situação de brinquedo e outra do cotidiano, antes e após a intervenção. Esta constou de dois encontros nos quais a mãe assistiu às filmagens e foi orientada quanto à sua conduta com relação à criança. Os resultados mostraram aumento no número de verbalizações maternas nas categorias informar e solicitar, bem como de falas da criança nas categorias falar espontaneamente e fazer solicitação, quando comparadas as medidas pré e pós-testes nas duas situações observadas. O estudo mostra a importância de intervenções que favoreçam a relação mãe-filho para o desenvolvimento de habilidades comunicativas da criança com deficiência auditiva e implante coclear.
\end{abstract}

Palavras-chave: relações mãe-criança; implante coclear; intervenção.

\section{Enhancing Interaction between Mother and Child Following Cochlear Implantation: A Case Study}

\begin{abstract}
The aim of this study was to evaluate the effect of an intervention made with the mother of a child following cochlear implantation through the evaluation of behavior changes identified after the program. Participants of the study were one mother and her deaf and cochlear implanted child, videorecorded during four observation sessions: in a playing and a daily situation, before and after the intervention. The intervention occurred in two meetings and involved practical orientations and the use of the videofeedback to help the mother analyse herself interacting with the child. Results showed that mother's speeches increased in two categories: giving information and making requests; as well as in the child's spontaneous speeches and making requests, when pre and pos-tests were compared in both situations. The study shows the importance of interventions which favour mother-child relations for the enhancement of a deaf and cochlear implanted child communicative skills.
\end{abstract}

Key words: mother-child relations; cochlear implantation; intervention.

O implante coclear tem demonstrado ser um método de tratamento eficaz na habilitação e reabilitação de pessoas com perda auditiva profunda, promovendo importante informação sensorial através da estimulação elétrica do nervo auditivo (Beadle, Shores \& Wood, 2000; Svirsky, Robbins, Kirk, Pisoni \& Miyamoto, 2000). Pode ser realizado em pessoas com surdez pré ou pós-lingual, ou seja, que adquiriram a deficiência auditiva, respectivamente, antes ou após a aquisição da fala. Em 1990, ele foi aprovado pela

1 Este artigo foi escrito com base na monografia apresentada pela primeira autora, sob orientação da segunda, ao Curso de Especialização em Psicologia Clínica do Hospital de Reabilitação de Anomalias Craniofaciais da Universidade de São Paulo, Bauru. Agradecemos à Prof ${ }^{a}$. Dra. Alessandra Turini Bolsoni-Silva pelas valiosas sugestões.

2 Endereço: Universidade Estadual Paulista, Faculdade de Ciências, Seção de Pós-Graduação. Av. Luiz Edmundo Carrijo Coube, 14-01, Vargem Limpa, Bauru, SP, Brasil 17033-360.E-mail: villares_ana@, yahoo.com.br
Food and Drug Administration (FDA) para ser realizado em crianças, a partir de dois anos de idade, que não poderiam ser beneficiadas pelo uso de Aparelhos de Amplificação Sonora Individual (AASI) (Bevilacqua, 1998). Entretanto, estudos mais recentes (por exemplo, Ertmer, Strong \& Sadagopan, 2003) indicam que o implante já pode ser realizado com crianças ainda mais jovens.

Segundo Svirsky e cols. (2000), o uso do implante coclear é benéfico e contribui significativamente para o desenvolvimento da percepção e produção da fala de crianças com surdez pré-lingual. Contudo, para Preisler, Tvingstedt e Ahlström (2002) perceber e reconhecer palavras e produzir ou imitar sentenças, não significa compreender o significado simbólico de uma palavra em particular ou frase ou, ainda, ser capaz de comunicar-se oralmente com outras pessoas. O significado simbólico, cultural, é aprendido nas relações com as pessoas. Segundo os autores, os resultados de um implante não devem ser medidos apenas em termos de percepção e 
produção da fala, o que caracteriza uma parte limitada do desenvolvimento da linguagem. É preciso ter uma perspectiva mais ampla do desenvolvimento da criança através da observação da sua relação com pais, pares e professores.

$\mathrm{O}$ ambiente em que a criança vive e a estimulação que recebe, principalmente da família, são essenciais para a promoção do seu desenvolvimento e desempenham um importante papel na aquisição da linguagem. Por isso, há uma grande preocupação dos profissionais sobre como oferecer suporte aos pais e orientá-los quanto à conduta com relação ao filho que recebeu o implante (Preisler, Ahlström \& Tvingstedt, 1997).

Segundo Brito e Dessen (1999), o diagnóstico da deficiência auditiva caracteriza-se como um momento traumático e desestruturador para a família e pode interferir na sua interação com a criança. A presença de um filho com deficiência pode gerar um estado de tensão nas interações entre criança e cuidador e provocar estresse parental (Burger \& cols., 2005).

De acordo com Janjua, Woll e Kyle (2002), os estudos sobre a interação entre pais e filhos chamam a atenção para o fato de que o estilo de interação parental tem um importante papel no desenvolvimento lingüístico da criança. Segundo os autores, as pesquisas que investigaram a relação entre pais e filhos com deficiência passaram a questionar se esta, de alguma maneira, alterava a interação entre eles e quais as consequiências para o desenvolvimento da criança. Os resultados dos estudos comparativos entre díades mãe ouvintecriança ouvinte e mãe ouvinte-criança surda, em geral, indicam que as segundas cuidadoras são mais dominantes e menos responsivas diante dos filhos, os quais, por outro lado, são menos participativos durante a interação.

McDonald e Pien (1982) destacam que as mães têm um modo peculiar de se dirigir aos filhos e que certas características da fala materna têm diferentes efeitos sobre o desenvolvimento da linguagem infantil. As autoras colocam, por exemplo, que, enquanto o uso de questionamentos pode favorecer a participação da criança na conversa, comportamentos diretivos revelam a intenção da mãe de controlar a interação.

O fato de os pais da criança com deficiência auditiva comportarem-se de maneira menos igualitária e espontânea e serem mais controladores nas interações, tomando mais iniciativa e dando poucas alternativas ao filho, pode prejudicar a comunicação. Quando a comunicação, por parte do adulto, é mais diretiva, aumenta a probabilidade de que a criança assuma uma atitude mais passiva e menos interessada nas trocas comunicativas (Marchesi, 1995).

Preocupados com a interação entre pais e filhos com deficiência auditiva, Janjua e cols. (2002) buscaram verificar a influência de diferentes estilos de interação sobre o desenvolvimento da linguagem. O estudo envolveu 13 mães e suas crianças com deficiência auditiva severa a profunda, usuárias de AASI, filmadas em uma situação de jogo e outra de brinquedo livre. Os resultados indicaram que as crianças com melhor desenvolvimento eram aquelas cujas mães apresentavam ações mais contingentes às da criança e maior envolvimento na interação. Os autores concluíram que o desenvolvimento da linguagem parece ser facilitado na medida em que as cuidadoras encorajam a participação da criança nas atividades e são mais responsivas diante das iniciativas comunicativas do filho, seguindo seus interesses em brincadeiras e conversas. Em outro estudo, Ertmer e cols. (2003) verificaram que os ganhos na linguagem de uma criança com implante coclear deviam-se, entre outras razões, aos esforços de seus pais para introduzir e reforçar sua fala, enfatizando o papel do mediador na aquisição das habilidades comunicativas observadas.

Outros pesquisadores (Harrigan \& Nikolopoulos, 2002; Beadle e cols., 2000; Preisler e cols., 1997) têm enfatizado a importância das interações no meio familiar para o desenvolvimento da pessoa com deficiência auditiva. No que diz respeito especificamente às crianças que recebem o implante coclear, os autores apontam para a importância dos membros da família no processo de habilitação após a cirurgia. Por isso, o trabalho dos profissionais deve ser o de tornar os pais os maiores envolvidos nesse processo (Archbold \& Tait, 2003).

Segundo Preisler e cols. (1997), as relações interpessoais que a criança estabelece é que servirão de contexto para sua socialização, para a emergência de competências básicas e para a aquisição de habilidades de comunicação. Pesquisadores têm ressaltado que é a motivação para comunicar-se verbalmente que apoia o desenvolvimento da linguagem que, como as habilidades comunicativas, está fortemente relacionada às experiências sociais da criança (Oliveira, 2002; Bat-Chava, Martin \& Kosciw, 2005).

Com o objetivo de investigar a comunicação de crianças implantadas em diferentes situações, Preisler e cols. (2002) realizaram um estudo de follow-up com 22 crianças implantadas, com idade entre dois e cinco anos, observadas na interação com familiares, professores e pares. Os resultados mostraram que as crianças mantinham uma comunicação mais significativa em casa do que na escola e que isso ocorria em função da disponibilidade dos adultos em atender às suas necessidades comunicativas.

Simser (citado por Harrigan \& Nikolopoulos, 2002) enfatiza que os pais devem ser vistos como o alvo principal de intervenções dos profissionais, aos quais se deve oferecer orientação quanto à estimulação das crianças para que se obtenham resultados positivos no estabelecimento da comunicação. Observar as relações entre o mediador e a criança com deficiência auditiva torna-se, então, um importante aspecto para a intervenção junto às famílias, uma vez que permite identificar necessidades e promover orientações para que se tornem comunicadores competentes.

Harrigan e Nikolopoulos (2002) desenvolveram um estudo com o objetivo de verificar a efetividade de um curso elaborado para desenvolver habilidades comunicativas de pais de crianças com implante. $\mathrm{O}$ estudo foi realizado com 17 pais em três encontros intercalados com visitas às casas das famílias, quando os pais foram filmados interagindo com os filhos. Posteriormente, os pais assistiram ao vídeo com o terapeuta e discutiram as mudanças que poderiam ser 
realizadas. Os resultados mostraram que, após o curso, os pais apresentaram comportamentos de iniciativa com menor freqüência (tornando-se menos diretivos e controladores nas interações) e aprenderam a ser mais responsivos diante das tentativas de comunicação das crianças. Segundo os autores, o curso foi bem aceito pelas famílias e provou ser efetivo na promoção de mudanças no comportamento de seus membros.

Os achados dos estudos apresentados apontam para a necessidade de se prover informações aos pais acerca das consequiências de uma interação facilitadora com os filhos e para a importância de ensiná-los como colocar isso em prática. Como afirmaram Janjua e cols. (2002), intervenções específicas e pontuais, tais como orientações práticas aos cuidadores, devem trazer consequiências positivas e contribuir para uma comunicação mais efetiva entre pais e filhos com deficiência auditiva.

Preisler, Tvingstedt e Ahlström (2005) verificaram que as crianças implantadas procuram se comunicar e interagir com outras pessoas e os obstáculos para estabelecer uma boa comunicação dificilmente são impostos pelas próprias crianças, mas pelos adultos. Elas precisam de cuidadores que respondam aos seus sinais e favoreçam as trocas comunicativas. Isso pode prevenir problemas no meio familiar e minimizar as dificuldades de alguns membros de interagir com a criança, ajudando-os a promover estimulação adequada para seu desenvolvimento.

O presente estudo de caso verificou os efeitos de uma intervenção para favorecer a qualidade da interação mãe-criança com implante coclear. Para tanto, teve como objetivos específicos: a) descrever e comparar os comportamentos de uma mãe durante interação com sua filha com implante coclear, antes e após a intervenção sistemática, em situação do cotidiano e de brinquedo livre e b) descrever e comparar os comportamentos da criança com implante coclear durante interação com sua mãe, antes e após a intervenção sistemática, em situação do cotidiano e de brinquedo livre.

\section{Método}

\section{Participantes}

Participou deste estudo uma díade mãe ouvinte-criança com implante coclear. A criança, do sexo feminino, tinha cinco anos de idade e deficiência auditiva neurossensorial bilateral profunda, de etiologia congênita. Recebeu o implante há dois anos e seis meses e fazia parte do programa de implante coclear de um centro de pesquisas vinculado a um hospital público do estado de São Paulo, especializado em anomalias craniofaciais. A família era de baixa renda, a mãe com 36 anos de idade, com ensino fundamental incompleto, trabalhava como diarista uma vez por semana, constituindo-se como a principal cuidadora da criança.

A seleção da díade deu-se em função de três critérios: pouca idade da criança, menor tempo de implante e residência na cidade.

\section{Material}

Para observação da interação da díade utilizou-se uma filmadora VHS e o brinquedo Crie e Monte (Brinquedos Bandeirante), composto por peças de plástico para encaixe. Trata-se de uma atividade não-estruturada, sem regras previamente definidas e que pode ser direcionada conforme escolha dos participantes, motivo que determinou sua seleção pela pesquisadora. Na situação do cotidiano, os objetos utilizados, além da filmadora, foram aqueles disponíveis na cozinha da residência da família.

Protocolos para registro dos comportamentos observados, um para a mãe e outro para a criança, foram elaborados com base nas categorias propostas por Braz e Salomão (2002). Os protocolos continham as categorias de comportamento distribuídas nas linhas (descritas nas Tabelas 1 e 2) e o tempo da filmagem, dividido em intervalos de 30 segundos, distribuídos nas colunas.

\section{Local}

As sessões de filmagem, nos períodos pré e pós-intervenção, foram realizadas na residência da díade. Os encontros da pesquisadora com a mãe, durante a intervenção, ocorreram em uma sala do centro de pesquisas de modo a garantir a privacidade e o ambiente necessário para assistir às filmagens sem interferências externas.

\section{Procedimento de coleta de dados}

Após aprovação pelo Comitê de Ética em Pesquisa da Instituição onde foi realizada a pesquisa, a responsável pela criança foi contatada via carta, e convidada a participar do estudo. Para registro da sua anuência em participar do trabalho, foi apresentada uma carta de informação sobre a pesquisa e um termo de consentimento livre e esclarecido que, após o esclarecimento das dúvidas, foram assinados.

As filmagens na residência, envolvendo uma situação do cotidiano e uma de brinquedo, foram sugeridas pela pesquisadora e os horários, definidos com a mãe, tanto antes quanto após a intervenção. Apenas na primeira visita, antes do início da coleta de dados, a díade foi filmada em atividade livre durante cerca de 15 minutos para dessensibilização diante da presença da filmadora e da pesquisadora, que não interagia com a mãe nem com a criança. Inicialmente, foi solicitado à mãe que interagisse com a criança na situação de brinquedo (tendo sido disponibilizado o jogo Crie e Monte). Em seguida, a mãe foi instruída a escolher qualquer atividade que fizesse parte do seu cotidiano com a criança, tendo ela escolhido a situação de preparação da refeição. A duração das filmagens variou para cada uma das situações e estava condicionada ao período de realização da atividade. Assim, a atividade de brinquedo teve a duração de 11 minutos e, a do cotidiano, de nove minutos e 30 segundos, tanto antes quanto depois da intervenção. 
Tabela 1. Descrição das categorias de comportamento materno.

\begin{tabular}{ll}
\hline \multicolumn{1}{c}{ Categorias } & \multicolumn{1}{c}{ Descrição } \\
\hline Comportamentos diretivos & Instruir a criança, chamar a atenção ou expressar objeção a algum comportamento da criança \\
Solicitar & $\begin{array}{l}\text { Fazer perguntas, sugerir o que fazer, pedir coisas } \\
\text { Positivo: elogiar, aprovar uma ação da criança, confirmar uma fala da criança, respondendo a questões ou } \\
\text { pedidos etc.; Negativo: desaprovar ação da criança }\end{array}$ \\
Informar & Descrever objeto ou ação \\
Incentivar & Incitar a participação da criança na atividade \\
Repetir sua própria fala & Dizer o mesmo enunciado duas ou mais vezes seguidas \\
Repetir a fala da criança & Parafrasear um enunciado prévio da criança \\
Ajudar & $\begin{array}{l}\text { Acompanhar a criança na realização de uma determinada tarefa fazendo parte dela com a criança ou oferecendo } \\
\text { dicas verbais ou físicas }\end{array}$ \\
Dar modelo & Realizar uma tarefa ou dizer palavras ou frases, a fim de demonstrar a criança como fazê-lo \\
Demonstrar atenção & Reagir verbalmente demonstrando interesse por um chamado da criança \\
Outros & Comportamentos não incluídos em outras categorias \\
\hline
\end{tabular}

\section{A intervenção}

Após a primeira sessão de filmagem, a pesquisadora assistiu às fitas e selecionou trechos da interação para serem discutidos com a mãe, considerando aqueles que apresentavam exemplos de comportamentos facilitadores da interação e aqueles em que seria possível propor mudanças. A intervenção consistiu em dois encontros para a discussão de cada situação, de brinquedo e do cotidiano, gravados em áudio para maior controle acerca das orientações dadas. Os encontros tiveram uma hora de duração e uma estrutura comum: inicialmente, a mãe assistia por inteiro a uma das situações filmadas junto com a pesquisadora que, posteriormente, solicitava uma avaliação sobre a interação. Após a avaliação materna, a pesquisadora reproduzia os trechos previamente selecionados, elogiando a atuação da mãe em alguns deles e sugerindo mudanças quando necessário, orientando e dando modelos sobre como agir em momentos específicos. A participante foi encorajada a ser mais responsiva diante das tentativas de comunicar-se da criança e a reagir de modo contingente frente às falas espontâneas e solicitações da filha. Orientou-se a mãe a estar atenta aos assuntos de interesse da criança para, então, oferecer esclarecimentos e orientações, destacar características e uso dos objetos, fazer sugestões de atividades etc. As intervenções também tiveram como objetivo auxiliar a participante a identificar as possíveis consequiências do seu comportamento sobre os comportamentos da criança.

Tabela 2. Descrição das categorias de comportamento da criança.

\begin{tabular}{ll}
\hline \multicolumn{1}{c}{ Categorias } & \multicolumn{1}{c}{ Descrição } \\
\hline Falar espontaneamente & Emitir qualquer comportamento verbal não precedido por uma pergunta da cuidadora \\
Fazer perguntas & Inquirir à cuidadora sobre fatos ou objetos do contexto \\
Responder perguntas & Diante de uma questão feita pela mãe, apresentar respostas verbais condizentes \\
Fazer uma solicitação & Fazer um pedido ou expressar um desejo para a mãe \\
Chamar a atenção & Requisitar, oral ou fisicamente, a atenção da mãe para dizer ou mostrar algo \\
Responder - não verbal & Reagir de maneira contingente a uma solicitação materna \\
Clarificar & Questionar diante do não entendimento de uma fala da mãe \\
Repetir a fala da mãe & Parafrasear uma fala prévia da cuidadora \\
Repetir a própria fala & Dizer o mesmo enunciado duas ou mais vezes seguidas \\
Outros & Comportamentos não incluídos em outras categorias \\
\hline
\end{tabular}




\section{Procedimento de análise dos dados}

Para análise do comportamento da mãe e da criança na interação, em cada situação, foram utilizadas categorias elaboradas a partir do sistema descrito por Braz e Salomão (2002), acrescidas de outras categorias de comportamentos observadas nas situações pré e pós-intervenção, de acordo com os objetivos do trabalho (Tabelas 1 e 2).

As filmagens foram assistidas e a frequiência dos comportamentos foi registrada nos protocolos de observação. $\mathrm{O}$ comportamento era registrado na primeira ocasião em que fosse observado dentro de cada intervalo de tempo estipulado, no caso, 30 segundos. Assim, utilizou-se um registro por amostragem de tempo, obtendo-se uma freqüência relativa de respostas.

\section{Resultados}

Para verificar os efeitos da intervenção implementada, foi realizada uma análise comparativa da frequiência das categorias comportamentais, da mãe e da criança, observadas antes e após a intervenção, nas situações de brinquedo e do cotidiano.

Das dez categorias de comportamento materno observa-

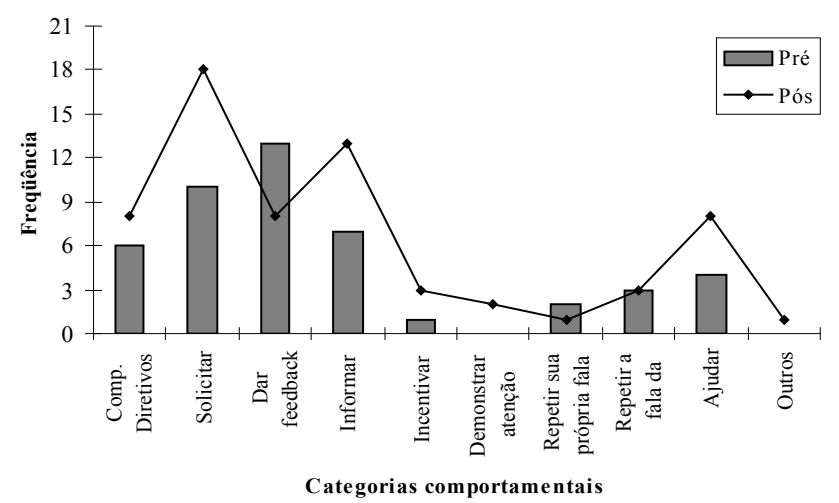

Figura 1. Frequiência dos comportamentos da mãe na situação de brinquedo, observados antes e após a intervenção.

das na situação de brinquedo, verificou-se variação positiva na frequiência relativa de sete, quando se compara as condições pré e pós intervenção, como apresenta a Figura 1. No total, foram feitos 46 registros do comportamento materno na primeira observação e 65 , na segunda, observandose uma variação positiva geral de 19 ocorrências. Todavia, algumas categorias merecem especial destaque, tendo em vista os interesses deste trabalho.

O número de registros na categoria ajudar dobrou da primeira para a segunda observação (de quatro para oito registros). Ao perceber o interesse da criança por alguma tarefa, a mãe passou a ajudá-la sem uma solicitação prévia, por exemplo, no momento em que olhou para filha que montava um jardim e a ajudou a encaixar as árvores. Além disso, verificou-se também variação de um para três registros na

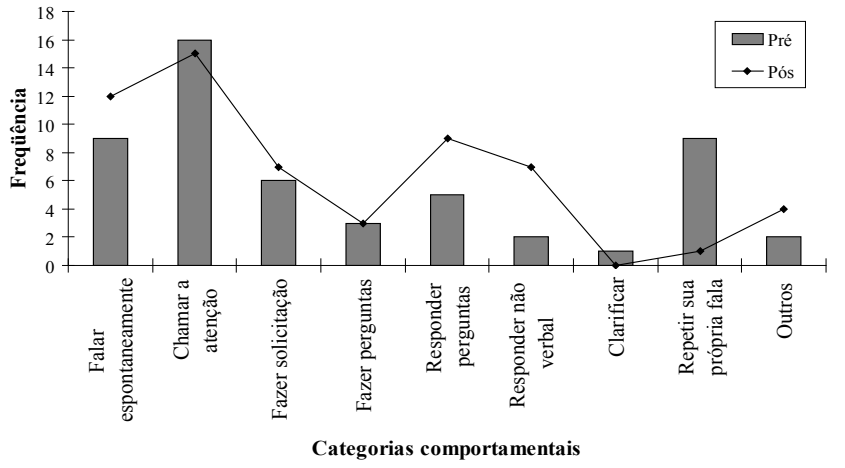

Figura 2. Frequiência dos comportamentos da criança na situação de brinquedo, observados antes e após a intervenção.

categoria incentivar, quando a mãe buscava favorecer a participação da criança na atividade.

Quanto ao informar (que aumentou de sete para 13 registros) observou-se que, após receber as orientações durante a intervenção, a mãe passou a descrever as características dos brinquedos ao perceber o interesse da filha por eles. Por exemplo, quando esta chamou sua atenção para mostrar uma casa, a mãe disse: "Aí, a janela da casa".

Em relação às solicitações maternas, verificou-se que, antes da intervenção, as perguntas feitas pela mãe consistiam apenas em questões fechadas, isto é, que requeriam respostas do tipo "sim" e "não". Após a intervenção, observou-se que as solicitações, que aumentaram de dez para 18 registros, passaram a envolver também perguntas abertas. Isto é exemplificado pela seguinte fala da mãe, no início da atividade: "O que a T. sabe fazer?".

Apesar do decréscimo de cinco registros no número de verbalizações maternas na categoria dar feedback, observou-se que, entre os comportamentos agrupados nesta categoria, dar feedback positivo apresentou aumento (com um registro na primeira filmagem e quatro na segunda). O feedback positivo passou a ser utilizado pela mãe também como elogio, por exemplo, com uso da expressão "Que lindo!” no momento em que a criança solicitou sua atenção para mostrar o objeto que construiu. Em outros momentos, verificouse que a mãe demonstrava aprovação à tarefa realizada pela filha através do uso da expressão "Isso!".

Tendo em vista que este estudo envolveu o comportamento materno na interação com a filha, foi registrado, também, o comportamento da criança, como apresentado na Figura 2, para a situação de brinquedo. Das nove categorias observadas na situação de brinquedo, verificou-se que cinco apresentaram variação positiva de respostas quando se compara as condições pré e pós-intervenção. No total, foram feitos 60 registros do comportamento da criança na primeira observação e 61, na segunda, observando-se uma variação positiva geral de uma ocorrência. Cabe citar que algumas das falas da criança não foram identificadas em função da pouca inteligibilidade das mesmas.

Duas categorias em que se verificou variação positiva da primeira para a segunda condição foram responder perguntas (de cinco para nove registros), que aumentou conforme 


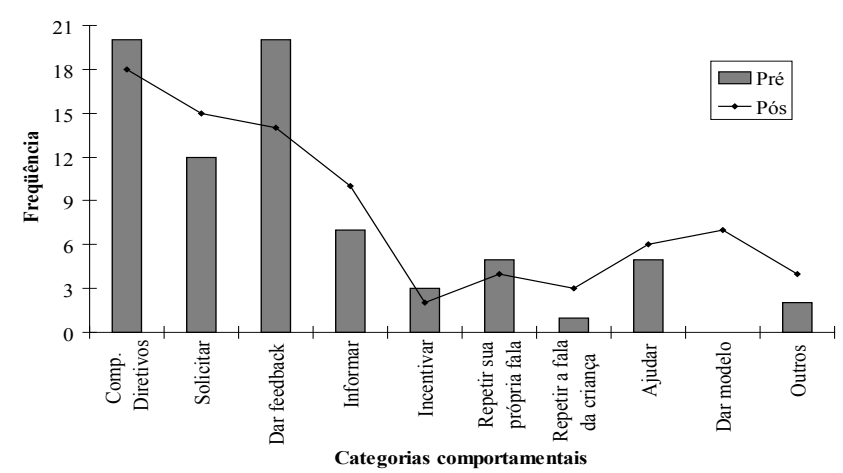

Figura 3. Frequiência dos comportamentos da mãe na situação do cotidiano, observados antes e após a intervenção.

as solicitações maternas e responder não-verbal (de dois para sete registros), o qual consistiu no seguimento de instruções dadas pela mãe e evidência da atenção da criança frente a um chamado materno.

Observou-se, também, aumento de nove para 12 registros na freqüência de falas espontâneas da criança, que se constituíram de informações a respeito dos brinquedos por ela utilizados e descrições sobre suas ações, com frases do tipo: "É uma casa, mãe" ou, ainda, "Tentar fechar", indicando sua ação subsequiente. Já as solicitações, com aumento de uma ocorrência, envolveram perguntas e pedidos feitos à mãe.

A Figura 3 apresenta a freqüência das categorias do comportamento materno na situação do cotidiano, que envolveu o momento de preparo da refeição. Seis das dez categorias identificadas apresentaram variação positiva na frequiência após a intervenção. No total, foram feitos 75 registros do comportamento da genitora na primeira observação e 83, na segunda, observando-se uma variação positiva geral de oito ocorrências.

Dos comportamentos observados destacaram-se: informar (que aumentou de sete para dez registros), solicitar (que variou de 12 para 15 registros) e ajudar (de cinco para seis registros). A categoria dar modelo foi registrada somente após a intervenção, com sete ocorrências, quando se observou que a mãe passou a ajudar e a dar modelos ao perceber dificuldade ou desconhecimento da criança em

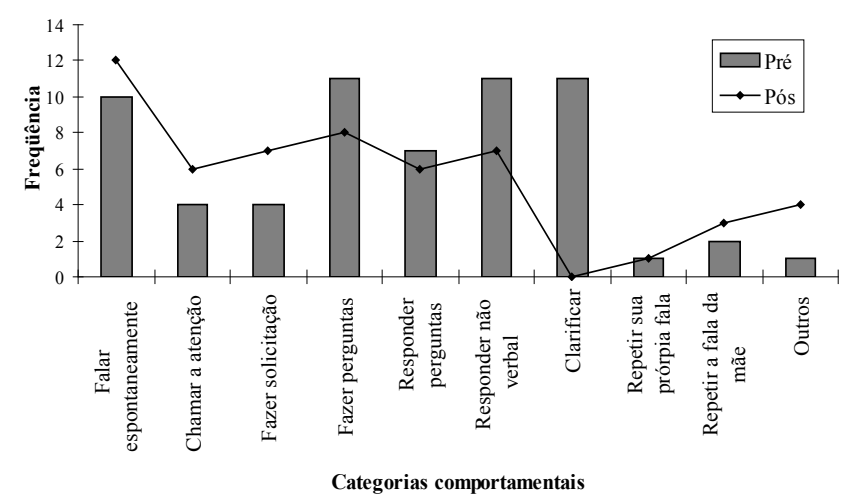

Figura 4. Frequiência dos comportamentos da criança na situação do cotidiano, observados antes e após a intervenção. determinada tarefa. Também nessa situação, na categoria solicitar, perguntas abertas passaram a ser mais freqüentes após a intervenção, bem como explicações sobre os objetos manuseados na categoria informar.

A categoria de comportamentos diretivos manteve uma alta frequiência da primeira observação (com 20 registros) para a segunda (18), ainda que fosse observado um decréscimo de dois registros.

A Figura 4 apresenta a freqüência das categorias de comportamento da criança na situação do cotidiano, nas condições pré e pós-intervenção. Cinco categorias comportamentais foram mais freqüentes após a intervenção. No total, foram feitos 62 registros do comportamento da criança na primeira observação e 54, na segunda, observando-se uma variação negativa geral de oito ocorrências. Apesar da variação observada, algumas categorias aumentaram da primeira para a segunda observação.

$\mathrm{Na}$ situação do cotidiano, o fazer solicitação, que aumentou de quatro para sete registros, foi tanto na primeira quanto na segunda filmagem, relacionado a pedidos, com falas como "Péra!", modo pelo qual a criança pedia à mãe que esperasse para que fizesse uma determinada tarefa.

O falar espontaneamente esteve, como na situação de brinquedo, relacionado à atividade e aumentou de dez para 12 registros. Na primeira filmagem, as falas da criança foram de nomeação e referiam-se aos objetos por ela manuseados. Na segunda filmagem, ocorreram também descrições sobre o que acontecia com a própria criança na atividade, com falas como "Eu sei!", usadas pela criança para indicar interesse em realizar alguma tarefa executada pela mãe.

\section{Discussão}

Uma intervenção pontual, com o uso de filmagens e realizada em poucos encontros, parece ter favorecido a qualidade da interação da díade contribuindo, de modo geral, para maior atenção da mãe com relação à filha e maior participação materna, principalmente, durante a atividade de brinquedo.

A intervenção proposta não só visou ao aumento das ações e verbalizações da mãe, mas também à qualidade da interação, tendo em vista que parece haver uma relação positiva entre a quantidade e qualidade da fala dirigida à criança e o desenvolvimento da linguagem (Nicholas \& Geers, 2003).

Observando as Figuras 1 e 3, que se referem ao comportamento materno, é possível perceber que, tanto na situação de brinquedo, quanto na do cotidiano, as categorias solicitar, informar e ajudar foram mais freqüentes após intervenção. Quanto aos comportamentos da criança, falar espontaneamente e fazer solicitação foram as categorias que apresentaram variação positiva em ambas as situações observadas, quando comparadas as condições pré e pós intervenção.

Quanto aos aspectos qualitativos, na situação de brinquedo, o fato de a cuidadora estar mais atenta aos comportamentos da criança na pós-intervenção permitiu que suas 
verbalizações fossem mais contingentes aos interesses da filha, o que pode ter favorecido, por conseguinte, maior participação da criança na conversa. Conforme o estudo de Janjua e cols. (2002), o desenvolvimento lingüístico pode ser favorecido na medida em que os pais apresentam mais ações contingentes e maior envolvimento nas interações com os filhos. A atenção dispensada pela mãe à filha e sua tentativa de explorar assuntos que despertassem a curiosidade da criança estão em conformidade com as discussões realizadas durante a intervenção, nas quais se destacou a importância da atenção materna para a construção de diálogos. Para Preisler e cols. (2002), adaptar a comunicação aos interesses da criança significa adotar uma postura centrada nesta, o que os autores consideram como um dos fatores facilitadores para o desenvolvimento de habilidades de comunicação da criança usuária do implante coclear. Além disso, observou-se que mãe e filha passaram a compartilhar a mesma tarefa por mais tempo, montando juntas as peças, o que possibilitou, conseqüentemente, maior atenção de ambas sobre o que a outra estava fazendo. Compartilhar tarefas pode criar oportunidades para uma comunicação mais significativa entre mãe e criança na medida em que proporciona a participação de ambas durante a atividade (Archbold \& Tait, 2003). Do mesmo modo, as falas de incentivo, mais freqüentes após a intervenção, podem cumprir um importante papel, tendo em vista que a interação parece ser facilitada na medida em que os pais não apenas atuam, mas também encorajam a participação da criança nas atividades (Janjua e cols., 2002). Outro aspecto observado que pode ter efeitos positivos é dar informações nomeando os objetos ou descrevendo as ações e acontecimentos ocorridos durante a atividade, que está relacionado com a aceleração da aquisição da linguagem (Hess \& Shipman, 1964, conforme citado por Matos, 1983).

Diversas situações evidenciaram a influência dos comportamentos maternos sobre os comportamentos da criança e vice-versa. Observou-se, por exemplo, o uso freqüente, por parte da mãe, da expressão "Isso!" como forma de dar feedback positivo à filha que, por sua vez, passou a imitá-la e fazer uso da mesma expressão para demonstrar aprovação diante do comportamento materno. Nesse caso, os comportamentos da genitora podem ter servido de modelo para a criança, o que se constitui em uma importante estratégia de aprendizagem de novos repertórios. Já as verbalizações da criança podem ter contribuído para a manutenção do uso do feedback positivo por parte da mãe. A imitação da fala materna pode ajudar ainda a enriquecer o vocabulário e aumentar a inteligibilidade da fala de crianças com implante (Ertmer e cols., 2003).

Diferentemente da situação de brinquedo, no preparo da refeição, observou-se o uso freqüiente de instruções maternas - comportamentos diretivos - presentes ao longo de toda a atividade, ainda que tenham diminuído da primeira para a segunda observação. Este comportamento parece ser decorrente da natureza da atividade, já que a criança encontrava-se em uma tarefa para ajudar a mãe e, possivelmente, necessitava de orientações. Apesar de alguns autores (por exemplo, McDonald \& Pien, 1982; Szagun, 1997) sugerirem relações negativas entre o uso de diretivos e o desenvolvimento da linguagem, há controvérsias quanto aos efeitos dos comportamentos diretivos (Braz \& Salomão, 2002). Parece que, na situação escolhida pela mãe, o preparo da refeição, o uso de instruções foi uma forma de ensinar e orientar a filha sobre formas de colaborar na atividade.

Além disso, observou-se que, no geral, a frequiência relativa de respostas maternas foi maior na situação do cotidiano do que na de brinquedo, tanto antes quanto após a intervenção, ainda que a duração das sessões de observação tenha sido semelhante. A hipótese levantada é de que se trata de uma tarefa do dia a dia com uma finalidade específica e cujo objetivo não é, unicamente, o de interagir com a criança, diferentemente da situação lúdica. Todavia, sem excluir a importância de aproveitar todas as situações para promover a comunicação da criança com as pessoas do seu ambiente, sugere-se que intervenções que visam sistematicamente aumentar a interação entre díades ou tríades devem explorar atividades centradas na criança para ensinar aos pais o que fazer para estimular seu filho.

As solicitações maternas, especialmente o uso de perguntas, que foram mais freqüentes em ambas as situações observadas, pareceram estar relacionadas à maior atenção dispensada pela mãe à filha. Snow (1977) afirma que a mãe que utiliza questionamentos o faz para manter a interação e favorecer a participação da criança na conversa, enquanto que Archbold \& Tait (2003) ressaltam que contribui, também, para o desenvolvimento de habilidades comunicativas. Ao menos na situação de brinquedo, observou-se aumento do responder perguntas por parte da criança, o que pode ser considerado consequiência do aumento nas solicitações feitas pela mãe, como mostraram as Figuras 1 e 2. O questionamento exige uma resposta verbal da criança, o que pode favorecer sua participação no diálogo e equilibrar suas verbalizações com as falas maternas, para que não haja apenas um elemento da díade falando. Para Ertmer e cols. (2003), o aumento de respostas às perguntas e de falas espontâneas da criança está relacionado ao fato de esta ter se tornado um comunicador mais competente, sendo capaz de dar continuidade à fala do outro e iniciar tópicos em uma conversa. Contudo, observou-se que nem sempre as perguntas feitas pela genitora foram respondidas pela criança; porém, em diversos momentos, nas situações pós-intervenção, a mãe as repetiu, aguardando, então, uma resposta da criança para continuar sua fala.

De modo geral, observou-se que a mãe olhou mais para sua filha após ser orientada sobre a importância de prestar atenção às ações da criança. Para Archbold e Tait (2003), atentar para o que a criança faz ou olha ajuda a identificar seus interesses e permite aos pais fazer comentários a respeito de temas que podem favorecer sua participação na conversa. Além disso, Preisler e cols. (2002) destacam que a principal contribuição da face para a comunicação é a de que revela o estado emocional do falante, bem como sua intenção diante do ouvinte. É possível supor que, através do olhar, a mãe tenha buscado evidenciar sua atenção diante 
da fala da criança, o que havia sido pouco observado antes da intervenção. Isso pode ter acontecido em decorrência da preocupação da cuidadora relatada nos encontros de que, se olhasse muito para a filha durante uma conversa, esta não estaria atenta aos sons da sua fala, mas ao movimento dos seus lábios como forma de compreender o que foi dito.

Com a atenção dispensada à mãe durante a intervenção, não só foi possível dar orientações, mas também esclarecer dúvidas quanto ao comportamento da filha. Os encontros realizados, além de terem contribuído para as mudanças observadas, podem ter favorecido a auto-observação da mãe em relação ao seu próprio comportamento. A intervenção foi bem aceita por ela, que a descreveu como um modo de estar constantemente aprendendo a lidar com a criança. Do mesmo modo, parece ter possibilitado a promoção de mudanças positivas nas suas habilidades comunicativas. Harrigan e Nikolopoulus (2002) também encontraram boa aceitação em seus programas para pais, o que indica que trabalhos desta natureza são bem recebidos de modo geral. A intervenção realizada no presente estudo pode ser particularmente útil aos profissionais que atuam no centro de pesquisas onde o trabalho foi desenvolvido. A reabilitação da criança implantada é feita ao longo dos anos durante o retorno das famílias, que geralmente permanecem poucos dias em atendimento no hospital. O uso de filmagens, ao contribuir para a autoobservação, pode favorecer as orientações prestadas pela equipe sobre a conduta dos pais em relação aos seus filhos.

O sucesso do implante coclear depende de diversos fatores, inclusive de como está organizado o ambiente da criança que o utiliza, especialmente no que diz respeito ao envolvimento dos pais no estabelecimento de uma interação efetiva com seus filhos. Preisler e cols. (2002) consideram que o bom funcionamento da comunicação da criança com seu cuidador não deve ser visado somente após o implante, mas deve ser estabelecido antes de ele ocorrer. Como afirmam os autores, "as possibilidades para a criança se engajar em uma interação significativa dependem, em grande parte, da habilidade do adulto de se adaptar à criança e dar espaço para que esta tenha participação ativa na interação" (p. 415).

\section{Considerações Finais}

Considera-se que a intervenção proposta favoreceu a interação da díade e que o videofeedback mostrou-se uma ferramenta eficaz para prover orientações à mãe sobre como agir em relação à filha. Ainda que tenham sido observadas mudanças, é importante destacar que algumas categorias de comportamento observadas apresentaram variação negativa ou mantiveram a frequiência quando comparadas as condições pré e pós-intervenção. Sugere-se, portanto, o planejamento de mais de uma sessão de observação e orientação alternadas, de forma que se possa orientar, repetir a experiência, reorientar, observar, etc. Além disso, é importante o envolvimento de outros membros da família e o uso de outros recursos além do videofeedback, como o role-playing, de modo que pais e irmãos possam interagir com o terapeuta durante as orientações e assim, terem modelos de como se comportar em relação ao membro da família que recebeu o implante coclear, especialmente, durante atividades lúdicas centradas na criança.

\section{Referências}

Archbold, S. \& Tait, M. (2003). Facilitating progress after cochlear implantation: reabilitation - rationale and practice. Em B. McCormick \& S. Archbold (Orgs.), Cochlear implants for young children (pp.257-301). London: Whurr Publishers Ltd.

Bat-Chava, Y., Martin, D. \& Kosciw, J. G. (2005). Longitudinal improvements in communication and socialization of deaf children with cochlear implants and hearing aids: evidence from parental reports. Journal of Child Psychology and Psychiatry, 46(12), 1287-1296.

Beadle, E. A., Shores, A. \& Wood, E. J. (2000). Parental perceptions of the impact upon the family of cochlear implantation in children. The Annals of Otology, Rhinology \& Laryngology. Supplement, 185, 111-114.

Bevilacqua, M. C. (1998). Implante coclear multicanal: uma alternativa na habilitação de crianças surdas. Tese de Livre Docência, Universidade de São Paulo, Bauru.

Braz, F. S. \& Salomão, N. M. R. (2002). A fala dirigida a meninos e meninas: um estudo sobre o input materno e suas variações. Psicologia: Reflexão e Crítica, 15(2), 333-344.

Brito, A. M. W. \& Dessen, M. A. (1999). Crianças surdas e suas famílias: um panorama geral. Psicologia: Reflexão e Crítica, 12(2), 429-445.

Burger, T., Spahn, C., Richter, B., Eissele, S., Löhle, E. \& Bengel, J. (2005). Parental distress: the initial phase of hearing aid and cochlear implant fitting. American Annals of the Deaf, 150(1), 5-10.

Ertmer, D. J., Strong, L. M. \& Sadagopan, N. (2003). Beginning to communicate after cochlear implantation: oral language development in a young child. Journal of Speech, Language, and Hearing Research, 46(2), 328-240.

Harrigan, S. \& Nikolopoulos, T. P. (2002). Parent interaction course in order to enhance communication skills between parents and children following pediatric cochlear implantation. International Journal of Pediatric Otorhinolaryngology, 66(2), 161-166.

Janjua, F., Woll, B. \& Kyle, J. (2002). Effects of parental style of interaction on language development in very young severe and profound deaf children. International Journal of Pediatric Otorhinolaryngology, 64(3), 193-205.

McDonald, L. \& Pien, D. (1982). Mother conversational behaviour as a function of interactional intent. Journal of Child Language, 9(2), 337-358.

Marchesi, A. (1995). Comunicação, linguagem e pensamento das crianças surdas. Em C. Coll, J. Palacios \& A. Marchesi (Orgs.), Desenvolvimento psicológico e educação: necessidades educativas especiais e aprendizagem escolar (pp. 198-214). Porto Alegre: Artes Médicas.

Matos, M. A. (1983). A medida do ambiente de desenvolvimento infantil. Psicologia, 9(1), 5-18.

Nicholas, J. G. \& Geers, A. E. (2003). Hearing status, language modality, and young children's communicative and linguistic behavior. Journal of Deaf Studies and Deaf Education, 8(4), 422-437. 
Oliveira, Z. M. R. (2002). Educação infantil: fundamentos e métodos. São Paulo: Cortez.

Preisler, G., Ahlström, M. \& Tvingstedt, A. L. (1997). The development of communication and language in deaf preschool children with cochlear implants. International Journal of Pediatric Otorhinolaryngology, 41(3), 263-272.

Preisler, G., Tvingstedt, A. L. \& Ahlström, M. (2002). A psychosocial follow-up study of deaf preschool children using cochlear implants. Child: Care, Health and Development, 28(5), 403-418.

Preisler, G., Tvingstedt, A. L. \& Ahlström, M. (2005). Interviews with deaf children about their experiences using cochlear implants. American Annals of the Deaf, 150(3), 260-267.

Snow, C. E. (1977). The development of conversation between mothers and babies. Journal of Child Language, 4(1), 1-22.

Svirsky, M. A., Robbins, A. M., Kirk, K. I., Pisoni, D. B. \& Miyamoto, R. T. (2000). Language development in profoundly deaf children with cochlear implants. Psychological Science, 11(2), 153-158.
Szagun, G. (1997). A longitudinal study of the acquisition of language by two German-speaking children with cochlear implants and of their mothers' speech. International Journal of Pediatric Otorhinolaryngology, 42(1), 55-71.

Recebido em 15.12.2005

Primeira decisão editorial em 06.03.2006

Versão final em 28.04.2006

Aceito em 31.05.2006

\section{CONGRESSO DA UNIÃO LATINO-AMERICANA DE PSICOLOGIA (ULAPSI)}

Por uma Psicologia por todos e para o bem de todos.

Data: 12 a 14 de Setembro de 2007

Local: Havana - Cuba

Informações:

http://www.ulapsi.org 


\section{INTERESSADO EM AGILIZAR A PUBLICAÇÃO DE SEU ARTIGO?}

\section{Informações e dicas para os autores sobre aspectos operacionais}

\section{O manuscrito é reencaminhado pelo autor em versão reformulada}

Quando a versão reformulada é aceita e são poucos os reparos, as correções necessárias são feitas na secretaria da revista. Com o disquete disponível, o processamento pode ser imediatamente iniciado. Na falta de disquete ou CD-R, não é possível o processamento de correções nem a preparação do manuscrito para editoração. Em suma, atraso para entrar no prelo.

\section{Informações e dicas para os autores com artigos no prelo}

\section{O manuscrito é encaminhado para editoração}

No caso de o manuscrito ser aceito para publicação, é esperada a participação do autor no processo de preparação do artigo na fase de editoração. A primeira prova do artigo, editada a partir da versão em disquete ou CD-R, é enviada para exame ao(s) autor(es). O prazo para devolução é de 48 horas. A obediência ao prazo permite a manutenção da composição prevista para o volume/número da revista. $\mathrm{O}$ atraso no envio da prova examinada pode implicar em mudanças na composição de um número no prelo. E pode resultar em atraso na edição final. 